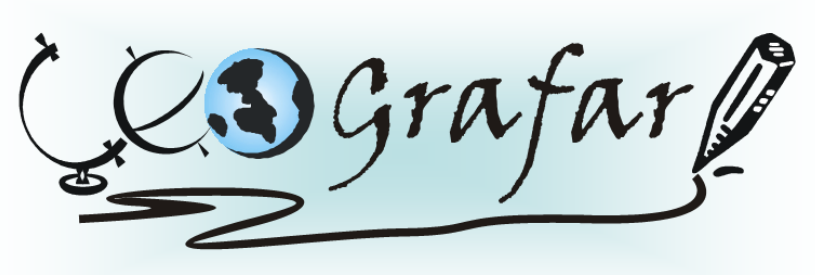

Revista Eletrônica do Programa de Pós-Graduação em Geografia - UFPR

\title{
EDUCAÇÃO AMBIENTAL E ALFABETIZAÇÃO CARTOGRÁFICA: CONTRIBUIÇÕES DE UMA EXPERIÊNCIA VIVIDA
}

\author{
JULIANA DE JESUS SANTOS ${ }^{1}$ \\ ODELFA ROSA ${ }^{2}$
}

\begin{abstract}
Resumo: Para se compreender o que o espaço Geográfico representa para uma sociedade, é preciso entender e conhecer o lugar de vivência de cada cidadão. A educação ministrada no meio rural se apresenta inadequada aos alunos desse meio, pois os conteúdos e a metodologia não atendem as necessidades próprias da realidade vivida pelos mesmos, impedindo assim, qualquer relação com a prática cotidiana. Nesta ótica, o entendimento da questão ambiental e o aprendizado da alfabetização cartográfica, deverão ser desenvolvidos e trabalhados com as crianças desde as séries iniciais. Ensinar os alunos as noções espaciais e obter informações sobre a questão ambiental é uma forma de promover a construção de procedimentos no sentido de desenvolver a capacidade das crianças de perceber seu entorno social e fazer sua representação.
\end{abstract}

Palavras-chave: Geografia; Alfabetização Cartográfica; Educação Ambiental.

\section{ENVIRONMENTAL EDUCATION AND LITERACY MAPPING: CONTRIBUTIONS OF AN EXPERIENCE}

\begin{abstract}
To understand what is the geographical area for a society, we must understand and know the place of living of each citizen. The education provided in rural areas appears inappropriate to the students of these places, because the content and methodology do not satisfied the requirements of the reality experienced by them what prevents, any relation with the daily practice. In this perspective, the understanding of environmental issues and the learning of literacy mapping should be developed and worked with children since first grades. To teach the students the concepts and how to obtain information about the environmental question is a way to promote construction of procedures to develop the capacity of children to understand their social environment and carry out their representation.
\end{abstract}

Keywords: Geography; Cartographic Literacy; Environmental Education.

\footnotetext{
${ }_{1}^{1}$ Aluna do Curso de Especialização em Pedagogia-UFG/CaC - juliana_ufg@yahoo.com.br

${ }^{2}$ Prof $^{2}$. Draํ. do Curso de Geografia - UFG/CaC - odelfa@uol.com.br
} 


\section{INTRODUÇÃO}

Atualmente, vivemos em um mundo em constantes transformações que alteram a natureza de muitas práticas sociais e ambientais. Hoje assimilamos novos tempos e espaços, onde as explosões tecnológicas, as informações e os conhecimentos se processam de forma acelerada provocando em nós, cidadãos, um pensar diferente com muitas possibilidades. Mudanças nas relações cidade-campo, alterações substanciais nas paisagens, desestruturação dos padrões culturais locais, dentre outros processos que aprofundam a separação do homem com a natureza. Assim a pesquisa teve como objetivo geral verificar a percepção dos alunos em relação ao conhecimento das noções espaciais (alfabetização cartográfica) bem como a educação para o meio ambiente proporcionando ao aluno um aprendizado consciente para prevenir os problemas ambientais a partir de seu entorno. Essas novas formas de viver e pensar exige uma reflexão profunda sobre o que é saber e sobre as formas de ensinar e aprender.

As tecnologias redimensionam o espaço da escola e, por sua vez, a sala de aula torna-se um ambiente de possibilidades de acesso às novas aprendizagens com as quais os alunos e professores possam interagir e aprender modificando a dinâmica das relações de ensino aprendizagem. O professor deixa de ser um mero transmissor de conteúdos e passa a atuar efetivamente no desenvolvimento curricular, levando o aluno perceber a realidade do entorno e desenvolver potencialidades capazes de favorecer a mudanças da realidade que se vive. Para Callai (2002, p. 101) "os currículos devem ser adaptados à realidade concreta e objetiva para que o aluno possa passar de mero consumidor de conhecimentos e seja também protagonista do processo ensino e aprendizagem".

Os conteúdos são instrumentos do processo de ensino-aprendizagem. Cavalcanti (2002) sugere que, ao escolhê-los, o professor priorize a formação do raciocínio espacial dos alunos, por isso, vá além da localização e descrição de determinados lugares e fatos isolados. Devem justificar essa localização e buscar significação dos lugares, considerando inúmeros aspectos, como os físicos, humanos, econômicos, culturais, geopolíticos, ambientais, cartográficos, além de 
outros articulados entre si. Os conteúdos, portanto, não podem estar desvinculados dos objetivos pedagógicos que orientam a escolha dos mesmos.

\section{A ESCOLA RURAL E AS SÉRIES INICIAIS}

A realidade social da educação é um tanto complexa, uma vez que ocorrem diversas mudanças desse fenômeno e articulam-se de modo especifico em diferentes espaços e momentos históricos. Nos últimos tempos, muitos teóricos tem procurado analisar o desempenho do sistema educacional brasileiro e suas relações com o desenvolvimento de novas tecnologias. Concomitante a este novo momento, tem-se um período escolar caracterizado por crises, seja da própria escola, seja do ensino de Geografia, onde o cotidiano da escola pública confronta-se com uma infinidade de desafios. Em alguns momentos de nossas vidas, são construídos conhecimentos que não são só resultado da vida na escola, ou seja, fruto exclusivo da educação dentro da Instituição. Estes conhecimentos são resultados também de nosso cotidiano e de nossas experiências a partir do espaço vivido.

A partir deste entendimento verifica-se a importância primordial que a escola da zona rural deve desempenhar tanto a nível econômico como a nível social dentro de uma comunidade. À escola, cabe importante papel, isto é o de restaurar o ponto de equilíbrio entre o mundo social emergente e a educação exigida por esse mundo em constante transformação. A formação adequada do cidadão, que se inicia nos primeiros anos de vida, deve se dar de modo que os indivíduos tenham condições para perceber e compreender uma dimensão de relações em tudo o que existe, e que Ihes possibilite o desenvolvimento pleno de sua própria dimensão relacional, considerando as conseqüências espaciais e temporais de sua multidimensionalidade.

No que se refere à escola, temos que considerar as séries iniciais no Ensino Fundamental com seu importante papel na definição da forma como nos relacionamos com a natureza (estudo do meio ambiente) e como nós representamos esses elementos da natureza sobre um plano que é o mapa (estudo das noções espaciais). Sobre isso nos parece essencial que trabalhemos o processo de 
aprendizagem para a compreensão da educação ambiental e das noções espaciais como a lateralidade, orientação, localização, referências, simbologia, legenda, escala considerando os conceitos da Geografia mais relevantes para os alunos nessa etapa da escolaridade. Assim, a compreensão desses conceitos são específicos para o desenvolvimento da alfabetização cartográfica em função de preparar o aluno para exercer atividades de observação, construção, manuseio e interpretação para o entendimento das representações gráficas.

Desde as primeiras etapas da escolaridade, o ensino de Geografia deve ter como objetivo mostrar ao aluno que cidadania é também o sentimento de pertencer a uma realidade em que as relações entre sociedade e a natureza formam um todo integrado do qual ele faz parte e que, conseqüentemente precisa conhecer, já que nos encontramos como membros participantes, comprometidos historicamente e contextualizados no mundo.

A formação consciente dos alunos (sujeitos) deve possibilitar, além da apropriação dos conhecimentos básicos, dentro de um contexto histórico e político dos direitos humanos e da cidadania, a mudança de valores, atitudes e posturas. Essa formação compreende a apreensão de uma nova cultura em que o educador se perceba, bem como perceba o aluno e os demais integrantes do trabalho escolar, como sujeitos de direitos e deveres, e veja a escola como espaço de exercício permanente de construção coletiva da cidadania. Segundo Freire (1996), "prender é construir, reconstruir, constatar para mudar a realidade que está posta. Esse processo só pode se dar a partir do momento em que o educando aprenda a realidade".

Paralelo a esse entendimento reforçamos que, na formação docente, é necessário privilegiar "conhecimentos específicos e outros mais amplos que garantirão ao profissional professor construir, em sua trajetória, uma autonomia pessoal e intelectual" (KATUTA, 2001, p.19). O processo de construção é, pois, uma tarefa que o estudante deve realizar, e o nosso desafio como professores é contribuir significativamente para o desenvolvimento de sua cidadania. Com essas ponderações, podemos considerar que a percepção sob o ângulo geográfico constitui-se um elo fundamental para compreender os diferentes aspectos da organização do espaço. 
Cabe, portanto registrar que, tudo que fazemos, dizemos, sentimos e percebemos em nossa vida diária, deve ser fonte de aprendizagem, pois está ligado em nossa vida e nas nossas necessidades concretas em nosso meio. A partir dessas reflexões faz-se urgente à necessidade de uma articulação da Licenciatura do curso de Geografia com a educação básica, assumindo um trabalho de qualidade junto aos professores que atuam nesse meio em escolas públicas.

Percebe-se dessa forma, a grande necessidade de direcionar o conteúdo de ensino valorizando a escola rural. Para se compreender o que o espaço Geográfico representa para uma sociedade, é preciso atender e conhecer o lugar de vivência de cada cidadão. O primeiro é fazer com que o aluno se reconheça como cidadão partindo do seu espaço conhecido, espaço próximo, de vivência, englobando espaços cada vez maiores. O segundo caminho é ensinar as habilidades espaciais fazendo com que o aluno aprenda a fazer a construção, representação, leitura e interpretação do espaço Geográfico.

Neste contexto é licito afirmar que a educação ministrada no meio rural se apresenta inadequada aos alunos desse meio, pois os conteúdos e a metodologia não atendem as necessidades próprias da realidade vivida pelos mesmos, impedindo assim, qualquer relação com a prática cotidiana. A esse respeito, Rosa (1999) coloca que:

O meio rural, com suas características próprias, não é considerado no atual modelo de escola e o desconhecimento de tais especificidades prejudica a escola, mesmo em suas funções básicas, como ensino de leitura, o ensino do cálculo e da escrita. A educação não leva em consideração a problemática específica da criança do meio rural, negando, inclusive sua cultura, sendo, portanto, uma extensão da educação urbana, onde não são considerados os interesses e as especificidades da população que ali vive. (ROSA, 1999, p. 17).

Contudo é importante destacar que há uma grande diferença entre a criança que vive no meio rural e a que vive no meio urbano. A grande maioria das crianças do meio rural não possuem uma infância e adolescência privilegiada, pois desde cedo aprendem a ter responsabilidades. Essas crianças não têm o espaço da brincadeira e o espaço do desenho livre para desfrutarem desse momento rico de detalhes, devido à participação da lida no campo. Entendemos, assim que, temos 
duas formas e modalidades da mesma educação que representam propósitos e finalidades diferenciadas.

Acredita-se que precisamos repensar novas metodologias de ensino, como, por exemplo, a utilização do livro didático e a atuação do professor. O professor necessita usar uma linguagem acessível ao aluno, levando-o a reflexão e a criatividade, estabelecendo novas estratégias de ensino-aprendizagem em que os alunos se sintam participantes ativos de seu espaço de vivência. Esses conhecimentos propiciam ao professor o entendimento de que sua tarefa passa pela formação da realidade, desvelando formas de avançar em uma aprendizagem com seres pensantes. Dessa forma, ao refletir sobre as possibilidades de encaminhamento de atividades educativas ambientais e cartográficas que possibilite a formação de uma consciência crítica do aluno, exige uma constante atualização do conhecimento e um grande desafio para os professores.

Para melhor elucidar a temática, as contribuições, especialmente da educação ambiental e educação cartográfica, tornam-se importantes por compreender, interpretar e representar os elementos da superfície terrestre. Assim, o tópico a seguir terá a incumbência de fazer a discussão sobre a educação ambiental e educação cartográfica realizada na Escola Ativa da zona rural de Catalão-GO.

\section{Educação Ambiental}

A Educação Ambiental emerge como uma proposta relevante em todos os níveis de ensino, dada a importância que as questões ambientais vem recebendo nas ultimas décadas. Visando o aprofundamento desse tema em questão, cabe colocar que educação ambiental não significa somente explicar como funcionam os ciclos naturais e incentivar os alunos que amem e respeitem as plantas, os animais , as aves e os rios. Os seres humanos vivem em sociedade e, em suas várias atividades, relacionam-se com a natureza e consequentemente com o meio ambiente. Cada sociedade tem um modo próprio de deixar marcas no meio ambiente. E nós seres humanos deixamos muitas marcas afetando cada vez mais nosso planeta. Essas marcas podem ser de desmatamentos, destruição, gastos 
excessivos, acúmulo de lixo em lugares impróprios, praguicidas, poluição e outros, resultando em graves conseqüências para o equilíbrio ambiental.

Aliados a essa situação, a educação ambiental não pode limitar-se a enfocar somente os elementos da natureza. É preciso passar para as crianças o incentivo, a divulgação, a informação, o conhecimento de formas alternativas para desenvolver um trabalho de conscientização das mesmas, acreditando que é a partir delas que se poderá sensibilizar o adulto para uma mudança de atitudes frente aos problemas abusivos dentro da comunidade local. Devemos despertar a consciência das crianças e jovens, informando-os sobre a importância da educação ambiental em diversas escalas, desde o atendimento a situações locais, regionais e até globais.

Deve-se ter em mente e considerar nos dias atuais as complexas relações de interdependência entre os diversos elementos da natureza, nos quais o homem se situa. Por sua vez o homem é capaz de conhecer e transformar a natureza atribuindo-Ihes significados e valores que se modificam com o passar do tempo e que ele se relaciona com a natureza por meio do trabalho (relações econômicas e sociais).Logo, é preciso ensinar aos nossos alunos fazer valer esses ideais de relações entre o homem e a natureza.Mas como podemos passar isso as nossas crianças, de que forma? Quais metodologias serão mais adequadas para o entendimento desse tema tão valoroso de nosso planeta?

A escola tem a função de atribuir conhecimentos básicos e úteis sobre a educação ambiental para que o aluno possa se situar partindo de seu espaço próximo interligando a realidade local, regional e mundial. Existem grandes dificuldades ao se programar um trabalho sobre educação ambiental nas escolas. Dentre essas dificuldades temos a sensibilização com o tema, a formação dos professores, implantação de atividades e projetos e a manutenção dos projetos já existentes. Destaca-se também alguns fatores como o tamanho da escola, número de alunos e predisposição dos professores em passar por um processo de treinamento.

Como então salvar nosso planeta da degradação ambiental? Devemos começar pela escola, com nossas crianças na disciplina de Geografia escolar, o que poderá resultar numa experiência rica e produtiva. Assim, a não degradação do nosso ambiente dar-se-á através da Geografia, por entre uma revolução de 
empenho na qual as crianças e as comunidades poderão diminuir as agressões contra nosso planeta. Neste sentido o meio ambiente e a Geografia escolar se encontram e este embelezamento ambiental tenta prende-se as relações humanas (crianças) baseadas no coletivismo, na diferença, no compromisso, na responsabilidade e na não violência para adotar atitudes coerentes em relação ao meio ambiente.

Deste modo, a escola continua a ser o local onde a cultura e o aprendizado se transformam, propiciando o surgimento de uma sociedade mais justa e igualitária despertando a atenção dos alunos pelos fenômenos naturais e sociais, juntamente com o sentimento de pertencimento a sua comunidade e a integração com o meio ambiente. Assim, para compreender a escola como um espaço possível de discussões sobre meio ambiente é necessário entrelaçar questões referentes ao lugar de vivência do aluno com o conhecimento geográfico (teoria-prática). Daí a importância de se atribuir à valorização da questão ambiental partindo da escola e, considerando a realidade concreta do espaço vivido do aluno. O aluno deve ser considerado não de forma abstrata, desligado da realidade em que vive, mas sim inserido no seu ambiente comunitário.

Para fugirmos dessa realidade que está posta, é necessário começarmos a nos mobilizar, aproximando currículo escolar e realidade local, principalmente no sentido de que haja uma valorização dos ambientes de vivência, para que neles se construa um processo de fortalecimento da relação aluno com o espaço geográfico de vivência. Acreditamos que para os conhecimentos escolares sejam entendidos e assimilados pelos alunos, os professores precisam enfrentar desafios tornando significativos os temas trabalhados em sala de aula. O longo caminho conhecido passa pelas questões atuais e vivência dos alunos, integrando diversos conteúdos e disciplinas, trabalhando de forma coletiva e aproximando a escola da comunidade e do mundo do trabalho e do aluno cidadão.

Nesse âmbito de considerações, é extremamente importante estudar o real (ambiente vivido), pois a partir do interesse do aluno, pode-se desencadear vários tipos de atividades para amenizar os problemas ambientais. Callai (2002, p.64) coloca que "o meio em que o aluno vive é rico em possibilidades de exploração, de 
desenvolvimento de atividades, por isso deve-se sempre ter o real, o que de fato existe, como ponto de partida para o estudo, [...]."

Enfim, tudo o que faz parte do cotidiano do aluno e sequer, muitas vezes, percebido por ele, mas que com criatividade, poderá ser explorado nas aulas práticas, fazendo com que o aluno aprenda a relacionar os conteúdos aprendidos em sala com a realidade que o cerca. Esta busca, em estar relacionando conhecimento (conteúdo) com a realidade, deve acontecer desde as séries iniciais, pois jamais haverá sucesso na aprendizagem escolar se os conteúdos forem inteiramente desvinculados do cotidiano dos alunos. O professor deve estimular 0 aluno a refletir a realidade na qual ele participa, fazendo-o entender que ele é um ser ativo no contexto social e histórico da sociedade em que vive. Assim, o aluno compreende que suas atitudes, por menores e insignificantes que sejam, irão refletir no meio ambiente sem perder de vista o local e fazendo uma ligação entre o regional e o global.

Dessa forma para conseguir que os alunos aprendam e que os conhecimentos escolares sejam úteis valorizamos o ambiente de vivência testando algumas atividades na Escola Municipal São Bernardes (Comunidade Tambiocó - Zona Rural pertencente ao Município) com temas relativos ao meio ambiente. Em um primeiro momento, discutiu-se com os alunos a preservação das matas daquele local, das cadeias alimentares, da atmosfera, das verduras, das leguminosas, da agricultura, da importância dos rios, entre outros aspectos cotidianos e culturais da comunidade.

Como podemos observar na foto 01 , as primeiras relações com o espaço na horta da escola, visto que os alunos começam a se interessar mais pela preservação da natureza e também em função das verduras dispostas para obtenção de uma boa saúde. Percebe-se a motivação dos alunos que trabalham com afinco na manutenção de uma horta feita por eles na própria escola, reconhecendo a importância e benefícios que a mesma trará, fruto da prática inicial de uma possível e contínua educação ambiental. 


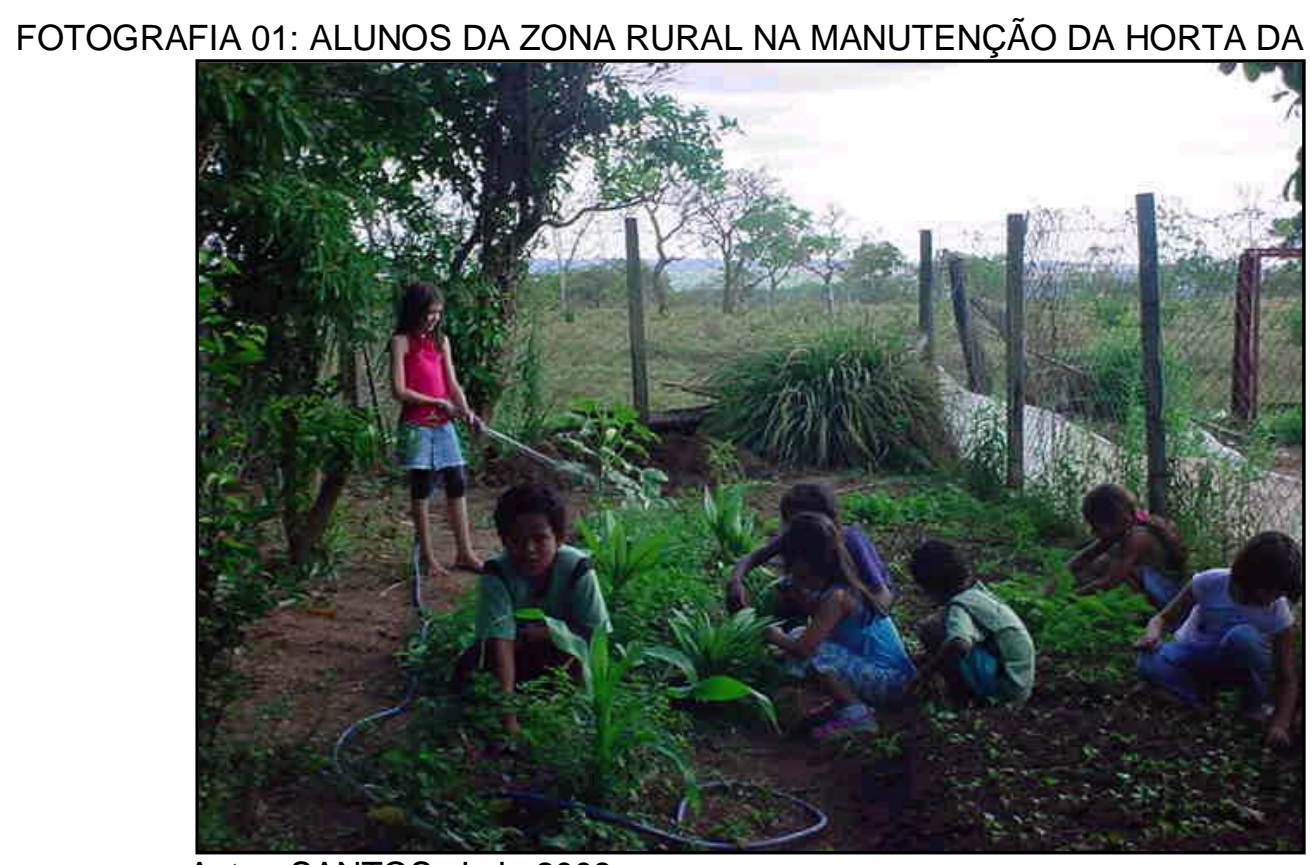

Autor: SANTOS, J. J., 2008

Acompanhando a atividade podemos dizer que essa ação possibilitou aos alunos uma compreensão mais ampla sobre as questões ambientais, mostrando que podem ser tomadas atitudes para enfrentar a situação que está posta diante de uma sociedade capitalista. Nessa perspectiva, estaremos cumprindo as funções da educação, sem as quais a escola se esvazia de seu significado social com o ambiente de vivência dos alunos. Portanto deveremos adotar medidas e ou atividades educativas que promovam a conscientização dos alunos conduzindo-os a comunidade a se organizar e a sentir-se responsável pelas paisagens onde moram, estudam, trabalham, praticam seus afazeres e passam suas vidas. Considerando assim, que alunos e comunidade possam atingir o limiar do conhecimento ou da ação, proporcionando atitudes mais efetivas para o controle do problema.

Por meio de troca de informações, discussões e reflexões o aluno formará uma nova mentalidade. Será capaz de trabalhar, efetivamente na busca de soluções para os problemas atuais e medidas preventivas para o futuro. Estas considerações nos permitem destacar que diante dos grandes desequilíbrios ambientais que se avolumam cada vez mais, a educação ambiental tem sido apontada como alternativa para amenizar os diversos problemas que tanto nos inquietam, sobretudo, na busca de melhor qualidade de vida e luta pelos direitos de cidadania. 


\section{Alfabetização Cartográfica}

Associado a Educação Ambiental temos a destacar a Alfabetização Cartográfica que ocupa um lugar relevante desde o inicio da escolaridade, contribuindo para que os alunos venham compreender e a utilizar um instrumento básico para leitura de mundo, os mapas. O mapa ajuda a compreender a dimensão de um determinado espaço, além de representar os elementos sobre a superfície terrestre. Contudo um dos grandes problemas levantado refere-se a não compreensão e construção do mapa por parte dos professores refletindo-se no aprendizado dos alunos. Assim, como podemos fazer a leitura do mapa se não aprendemos a trabalhar com noções espaciais que envolvem a lateralidade, orientação, localização, proporção, legenda e simbologia? De que forma os professores podem repassar o conteúdo, se não tiveram um aprendizado adequado em relação a esse tema?

Nesta ótica, o entendimento e aprendizagem da alfabetização cartográfica deverá ser desenvolvida e trabalhada com crianças desde as séries iniciais. A alfabetização cartográfica adquire um conhecimento concreto através de um processo lento e gradual pelas crianças e contribui para a formação da cidadania através da prática de construção das habilidades, noções espaciais e conceitos cartográficos.

Esses conceitos são conhecimentos que ampliam a capacidade dos alunos de compreenderem o seu espaço real. Para fazer a interpretação da realidade, a criança precisa atribuir significado ao elemento identificado e representado. Isto significa entender a extensão dos elementos representados e a forma como eles são organizados. Isso não se aprende tudo de uma vez, é preciso que o professor esteja atento em qual fase de desenvolvimento a criança se encontra, para poder interferir no processo de construção, isto é os primeiros passos para o entendimento das habilidades espaciais.

Dizemos então que, é no desenvolvimento das noções espaciais que o aluno estará adquirindo embasamento para 0 entendimento das representações cartográficas e do espaço geográfico. Para contribuir significativamente com 0 desenvolvimento da cidadania, a criança precisa valorizar o aprendizado espacial 
frente ao espaço percebido, vivido e aprender a construir seus próprios mapas de uma forma interativa associando os conhecimentos que já possui aos que acrescentamos dentro de sua realidade.

Preocupados com essa questão, não devemos nos esquecer que a cartografia deve ser ensinada nas séries iniciais, tendo como início a alfabetização cartográfica que compreende uma série de aprendizagens necessárias para que os alunos possam continuar sua formação nos elementos e representação gráfica, para posteriormente trabalhar com a representação cartográfica. Destarte, a continuidade do trabalho com a alfabetização cartográfica deve considerar o interesse que as crianças e jovens tem pelas imagens, atitude fundamental na aprendizagem cartográfica.

Porém, para alcançar os objetivos da alfabetização cartográfica, os alunos devem encontrar significados, estimulando a busca de informações que as imagens contem. Temos por características básicas da alfabetização cartográfica o desenvolvimento da capacidade de leitura, comunicação oral, e representação simples do que está impresso nas imagens, desenhos, plantas e maquetes. Dessa forma, podemos concluir que o aluno precisa aprender os elementos básicos da representação cartográfica para que possa, definitivamente, ler o mapa. Rosa (1999) ressalta que:

\begin{abstract}
Ensinar os alunos a ler e obter informações em diferentes tipos de mapas é uma forma de promover a construção de procedimentos que lhes permitem localizar objetos e lugares para se deslocarem com sucesso. Esses procedimentos também Ihes possibilitam utilizar os mapas enquanto fontes de pesquisa que sintetizam informações sobre lugares, regiões e territórios e diferentes partes do Brasil e do mundo. Aprender a ler mapas, bem como saber utilizá-los como uma representação do espaço que segue as regras dos vários sistemas de projeção e tem uma linguagem específica, é essencial para a formação do cidadão autônomo. (ROSA, 1999, p.52).
\end{abstract}

Nesse sentido, o professor pode planejar situações nas quais os alunos das séries iniciais da zona rural tenham que representar a própria casa, com o objetivo de mostrar aos colegas como ela é, ou a própria escola na sua comunidade, com o objetivo de informar sua estrutura para visitantes que não a conhece. Consolida-se assim, um trabalho no qual existe a interface entre o ensino da cartografia e as 
demais áreas do currículo. Os alunos aprendem a conhecer os mapas como fonte preciosa de informação.

Nesse sentido, ao elaborarmos as atividades a serem testadas e relacionadas ao entendimento do mapa (cartografia), tivemos o cuidado de produzir questões que procurassem desenvolver o raciocínio lógico em relação ao espaço conhecido do aluno. Para o desenvolvimento da atividade esclarecemos aos alunos que é interessante trabalhar com o mapa localizando a escola, seu entorno, as comunidades, os distritos e cidades dos sujeitos participantes. Com destaque importante também os elementos cartográficos como o titulo, localização, orientação, legenda, proporção, escala e símbolos. Na seqüência fizemos alguns questionamentos aos alunos: qual o nome de seu Município? Como é a paisagem de seu Município? Seu Município tem fábricas e indústrias? E o meio ambiente é preservado?E assim outras questões foram sendo trabalhadas com os participantes enfatizando os elementos do mapa, conforme podemos verificar na foto 02 . Percebe-se a empolgação dos alunos de $5^{\circ}$ ano em contato com o mapa, devido ser um tipo de atividade diferente para eles em sala de aula.

Cabe acrescentar que os alunos tiveram certas dificuldades para 0 entendimento dos elementos cartográficos, porém após alguns esclarecimentos sobre os mesmos eles foram capazes de interpretar com mais atenção o mapa exposto sobre o chão da sala de aula. Ao longo da atividade fomos explicando que o Município é um lugar que precisa ser entendido estabelecendo-se ligações entre o local, o regional, o estadual e internacional. Por ser importante conhecer o Município e seu entorno, é necessário pensar o processo ensino-aprendizagem a partir da compreensão do espaço que se vive, de sua cultura, seus valores, bem como questões políticas e sociais.

No decorrer da atividade os alunos puderam demonstrar seu encantamento pelo mapa, considerando alguns elementos básicos para a leitura e interpretação da representação trabalhada. Além disso, acreditamos que, conhecendo com mais afinco o documento que é o mapa os participantes poderão se interessar mais pelas questões cartográficas que assume um papel importante ao considerar os referenciais que os alunos conhecem para se localizar e orientar no espaço. 


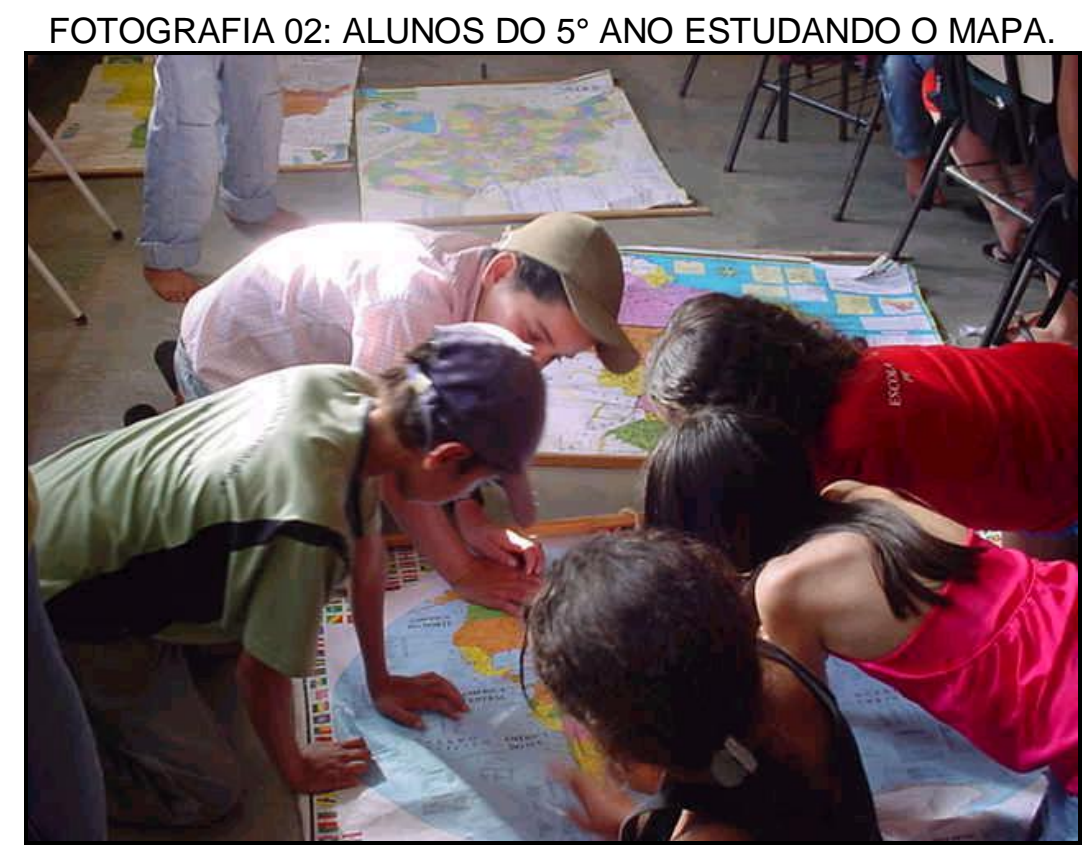

Autor: SANTOS, J. J., 2008

Para contribuir com o desenvolvimento da cidadania, torna-se importante que os professores possam auxiliar as crianças desde as séries iniciais a desenvolver habilidades com destaque para o estudo do lugar, espaço próximo e vivido dos alunos. A compreensão da experiência dos indivíduos em relação à leitura da realidade espacial, para Francischett (2002) dá-se pelo entendimento das representações existentes entre os elementos do espaço e a simbologia representativa da cartografia.

Essa constatação, porém, é muito importante para que o conteúdo das aulas de Geografia e Cartografia seja trabalhado de forma que os alunos construam sua própria cidadania e percebam seu cotidiano de forma crítica. O processo de alfabetização cartográfica possibilitará as crianças conhecer o espaço vivido (local). Frente a isso, Perez nos relata que,

alfabetizar no conteúdo do mundo é, do ponto de vista da Geografia, identificar na natureza tecnicamente produzida as contradições, em que estamos inseridos, procurando desvendar as ações necessárias a construção de um novo mundo, de uma nova natureza, na qual o ato humano tenha identidade de sua humanidade (PEREZ,2001, p.107).

Esse espaço deve ser conhecido através da compreensão e da experiência dos indivíduos, extrapolando para espaços mais distantes, através da percepção 
visual que pode fornecer importantes elementos cartográficos para entender a construção da realidade. Nessa ótica, o processo de ensino-aprendizagem com participação da cartografia, assume uma importância singular, pois prepara o professor e o aluno para reconhecer a história do meio em que vivem garantindo uma relação direta com a realidade local e as explicações gerais de um espaço mais distante.

As constantes transformações na esfera política, cultural, econômica e social fazem com que os estudos de cunho geográfico e cartográfico tornem-se cada vez mais relevantes e próximos das múltiplas realidades produzidas na dinâmica contemporânea. A Geografia e a Cartografia contribuem de maneira significativa para a interpretação das diferentes formas de organização na sociedade, possibilitando a integração entre as escolas. Diante dessa dinâmica, a escola tornase, cada vez mais, uma Instituição voltada para atender as características que a sociedade moderna lhe impõe, precisando acrescentar novos padrões de ensino. A necessidade de estudos relacionados à alfabetização cartográfica e de sua compreensão são inquestionáveis, pois o professor necessita desenvolver um trabalho com a criança em relação ao espaço perceptivo, espaço cognitivo e espaço do desenho que varia de acordo com cada indivíduo.

\section{METODOLOGIA DA PESQUISA}

A trajetória da pesquisa envolveu a Escola Ativa localizada na zona rural no Município de Catalão-GO e a metodologia de caráter qualitativo foi utilizada. Uma revisão de literatura pertinente a temática, leitura de obras referentes à educação cartográfica e ambiental, bem como Parâmetros Curriculares Nacionais do Ensino Fundamental se fizeram presentes em nossas discussões. A preparação do material foi realizada entre março e abril de 2008 e a coleta de dados na escola campo com alunos do 5a ano do Ensino Fundamental ocorreu em maio, junho e inicio de julho.

Num primeiro momento, trabalhou-se com a turma em sala de aula, fazendo um diagnóstico inicial sobre o conhecimento das temáticas levantadas, considerando as informações trazidas pelos mesmos. Dentro do contexto específico desta aula, 
esclarecemos as dúvidas manifestadas pelos alunos. Concomitante a isso, foram realizadas explicações inerentes aos temas trabalhados.

No que diz respeito à temática ambiental, trabalhamos a prática, considerando a paisagem no entorno e a horta da escola. Posterior a esse momento, foram feitos questionamentos aos alunos sobre o desmatamento da região, poluição de rios, erosões do solo, comparativo entre o ambiente rural e urbano, entre outros. Em relação à temática cartográfica, utilizamos várias aulas para trabalhar as noções espaciais e após foram desenvolvidas atividades sobre o mapa, localizando a escola no Município e estabelecendo relações entre o local, regional, estadual e nacional. A interpretação dos resultados demonstrou que essa pesquisa tornou-se de fundamental importância à medida que contribui para a melhoria da educação cartográfica e ambiental.

\section{CONSIDERAÇÕES FINAIS}

A sociedade cumpre um dever fundamental ligado ao bem estar individual, face as próprias exigências que crescem à medida que torna-se mais complexas as relações sociais, econômicas, políticas e culturais. Por sua vez, a escola da zona rural deve atender as necessidades e interesses da comunidade, estas não podem ser pensadas de maneira isolada uma vez que devem desempenhar papeis estratégicos na construção de um modelo de desenvolvimento. O espaço escolar deve ser compreendido por meio de conhecimentos significativos, levando-se em conta as relações construídas pelos alunos em seu espaço de vivência, por meio de experiências diárias de seu entorno.

O aluno deve perceber o seu entorno e desenvolver potencialidades capazes de favorecer mudanças na realidade em que vive, começando pela conscientização e preservação do meio ambiente. A conscientização do aluno deve possibilitar, além da apropriação dos conhecimentos básicos, de acordo com um contexto histórico e político dos direitos humanos e da cidadania, a mudança de valores, atitudes e posturas. Essa formação compreende a apreensão de uma nova cultura em que o professor se perceba e também perceba seu aluno e os demais integrantes do trabalho escolar e da comunidade como sujeitos, para que veja a escola como 
espaço de exercício permanente de construção coletiva de cidadania. Assim, tornase necessário reconhecer e valorizar os saberes e os conhecimentos dos diferentes sujeitos, tanto em relação à aprendizagem, quanto à própria produção de conhecimento. Nessa perspectiva, a cidadania se revela para o aluno como necessidade de adquirir conhecimentos, conceitos, procedimentos básicos por meio dos vários conhecimentos e informações condizentes com a realidade local.

Dessa forma, a elaboração e desenvolvimento da pesquisa, buscou compreender questões referentes a educação ambiental e o processo de construção de conhecimentos geográficos ( alfabetização cartográfica), mediante conteúdos teóricos expostos aos alunos e, posteriormente atividades práticas envolvendo a leitura de mapa e o contato com o meio ambiente por meio de atividades trabalhadas na paisagem do entorno e a horta da escola. Todo esforço aplicado à pesquisa constituiu-se na busca de respostas referentes aos problemas ambientais da comunidade onde se localiza a escola e o entendimento das noções espaciais pelos alunos. Os resultados obtidos por meio das atividades indicam que os alunos apresentam certa deficiência em relação às questões espaciais. Em relação à questão ambiental os alunos com A trajetória da pesquisa envolveu a Escola Ativa localizada na zona rural no Município de Catalão-GO e a metodologia de caráter qualitativo foi utilizada. Uma revisão de literatura pertinente a temática, leitura de obras referentes à educação cartográfica e ambiental, bem como Parâmetros Curriculares Nacionais do Ensino Fundamental se fizeram presentes em nossas discussões. A preparação do material foi realizada entre março e abril de 2008 e a coleta de dados na escola campo com alunos do $5^{\circ}$ ano do Ensino Fundamental ocorreu em maio, junho e inicio de julho e após foram feitas as interpretações dos resultados. Essa pesquisa tornou-se de fundamental importância à medida que contribui para a melhoria da educação cartográfica e ambiental.

preenderam a importância de preservar o meio ambiente e conscientizar a comunidade local da necessidade de trabalhar em busca de soluções e medidas preventivas para um planeta mais saudável

Acreditamos que as atividades práticas contribuem mais eficazmente para uma nova mentalidade entre os alunos, pois, por meio da ação ocorre a construção de conhecimentos significativos que Ihes serão úteis no decorrer de sua vida. Assim, a 
educação ambiental e a educação cartográfica, possuem papeis importantes em se tratando de fornecer instrumentos e conhecimentos elementares para que os alunos possam enfrentar seu cotidiano com consciência e interatividade com seu ambiente. Os resultados desse trabalho foram extremamente positivos uma vez que, além de terem tido o contato com a realidade, os alunos tiveram a oportunidade de obter uma visão de conjunto de um local conhecido.

\section{REFERÊNCIAS}

CALLAI, H. C. O Meio Ambiente no Ensino Fundamental. In: Dossiê: Os PCNs em discussão. Revista Terra Livre, São Paulo, Associação dos Geógrafos Brasileiros, $\mathrm{n}$ 13, p. 9-19, 1997.

Estudar o lugar para compreender o mundo. In: CASTROGIOVANNI, Antonio Carlos. Ensino de Geografia: práticas e textualizações no cotidiano. Porto Alegre: Editora Mediação, 2002, p. 83-134.

CAMPOS, M. das D. CATALÃO: Estudo Histórico e Geográfico. Goiânia: Tipografia e Editora Bandeirante, 1976, p.15-30.

CASTELLAR, S. M. V. A Formação de Professores e o Ensino de Geografia. In: As transformações no Mundo da Educação: Geografia, ensino e responsabilidade social. Revista Terra Livre, Associação dos Geógrafos Brasileiros, n 14, p.49-55, 1999.

CAVALCANTI, L. S. Geografia e práticas de ensino. Goiânia: Alternativa, 2002.

CHAVES, M. R; SILVA, K. C e ROSA, O. Valorizar o lugar e transformar o espaço de vivência: uma contribuição do ensino da Geografia à cidadania na educação básica em catalão (GO). Universidade Federal de Goiás - Pró - Reitoria de Graduação. Relatório final de Pesquisa do PROLICEN, 2004. (inédito).

FRANCISCHETT, M. N. A Cartografia no ensino da geografia: construindo os caminhos do cotidiano. Rio de Janeiro: Litteris Kroart.2002.

FREIRE, P. Pedagogia da Autonomia: saberes necessários a prática pedagógica São Paulo: Paz e Terra, 1997.

FREITAS, M. I. C. de; LOMBARDO, M. A. (Orgs) Universidade e Comunidade na Gestão do Meio Ambiente. LOMBARDO, M. A. In: Educação Ambiental como Subsídio à Escola do Futuro - Rio Claro, SP. 2000, p. 29-62.

KATUTA. A. M. As dificuldades dos alunos de $5^{\underline{a}}$ e $8^{\text {a }}$ séries no uso de redes geográficas e sua conceituação. In: Boletim de Geografia. Maringá - PR, v. 19, n. 2, p. 179-186, 2001. 
MOREIRA, R. Um mundo experimentando por inteiro. In: CONGRESSO BRASILEIRO DE GEÒGRAFOS, 5., 1994, Curitiba. Anais. Curitiba-PR: AGB, 1994, p.571-578.

PEREZ. C. I. V. Leituras do Mundo/Leituras do Espaço: Um diálogo entre Paulo Freire e Milton Santos. In: GARCIA, R. L. Novos Olhares sobre a alfabetização. São Paulo. Cortez, 2001.

ROSA, O. A Cartografia na Escola Rural - Ações e Proposições para 5 a série: um estudo de caso. Dissertação de Mestrado. Presidente Prudente: USP, 1999.

(Recebido em maio/2009. Aceito em novembro/2009) 